\title{
Whole-Body Microbiota of Sea Cucumber (Apostichopus japonicus) from South Korea for Improved Seafood Management ${ }^{\text {[S }}$
}

\author{
Tae-Yoon Kim ${ }^{1,3}$, Jin-Jae Lee ${ }^{1,3}$, Bong-Soo Kim ${ }^{1,3 *}$, and Sang Ho Choi ${ }^{2,3 *}$ \\ ${ }^{1}$ Department of Life Science, Multidisciplinary Genome Institute, Hallym University, Chuncheon 24252, Republic of Korea \\ ${ }^{2}$ Department of Agricultural Biotechnology, Center for Food Safety and Toxicology, Seoul National University, Seoul 08826, Republic of Korea \\ ${ }^{3}$ Food-borne Pathogen Omics Research Center (FORC), Seoul National University, Seoul 08826, Republic of Korea
}

\author{
Received: July 27, 2017 \\ Revised: August 24, 2017 \\ Accepted: August 28, 2017 \\ First published online \\ August 31, 2017 \\ ${ }^{*}$ Corresponding authors \\ B.S.K. \\ Phone: +82-33-248-2093; \\ Fax: +82-33-256-3420; \\ E-mail: bkim79@hallym.ac.kr \\ S.H.C. \\ Phone: +82-2-880-4857; \\ Fax: +82-2-873-5095. \\ E-mail: choish@snu.ac.kr
}

S upplementary data for this paper are available on-line only at http://jmb.or.kr.

pISSN 1017-7825, eISSN 1738-8872

Copyright(C) 2017 by

The Korean Society for Microbiology and Biotechnology
Sea cucumber (Apostichopus japonicus) is a popular seafood source in Asia, including South Korea, and its consumption has recently increased with recognition of its medicinal properties. However, because raw sea cucumber contains various microbes, its ingestion can cause foodborne illness. Therefore, analysis of the microbiota in the whole body of sea cucumber can extend our understanding of foodborne illness caused by microorganisms and help to better manage products. We collected 40 sea cucumbers from four different sites in August and November, which are known as the maximum production areas in Korea. The microbiota was analyzed by an Illumina MiSeq system, and bacterial amounts were quantified by real-time PCR. The diversity and bacterial amounts in sea cucumber were higher in August than in November. Alpha-, Beta-, and Gammaproteobacteria were common dominant classes in all samples. However, the microbiota composition differed according to sampling time and site. Staphylococcus warneri and Propionibacterium acnes were commonly detected potential pathogens in August and November samples, respectively. The effect of experimental Vibrio parahaemolyticus infection on the indigenous microbiota of sea cucumber was analyzed at different temperatures, revealing clear alterations of Psychrobacter and Moraxella; thus, these shifts can be used as indicators for monitoring infection of sea cucumber. Although further studies are needed to clarify and understand the virulence and mechanisms of the identified pathogens of sea cucumber, our study provides a valuable reference for determining the potential of foodborne illness caused by sea cucumber ingestion and to develop monitoring strategies of products using microbiota information.

Keywords: Microbiota, sea cucumber, foodborne illness, potential pathogen

\section{Introduction}

The sea cucumber (Apostichopus japonicus) is an epibenthic animal living in temperate habitats in the western Pacific Ocean and Yellow Sea [1]. A. japonicus ingests organic matter in the sediment, including bacteria, protozoa, and diatoms, as well as algae, and thus plays an important ecological role in the benthic ecosystem and nutrient recycling [2]. A. japonicus has been used as traditional medicine owing to its beneficial health properties, including anticoagulant, antifungal, and antitumor activities, as well as a seafood product in sushi restaurants $[1,3,4]$. The production of sea cucumber had decreased owing to overfishing, and in 2013 this species was listed as "Endangered" on the IUCN Red List of Threatened Species [5]. However, its population has begun to increase in recent years through seed production and aquaculture [6]. Raw sea cucumber is often eaten in sushi restaurants and is found in other popular food items in Korean restaurants. However, similar to raw oysters, the ingestion of raw sea cucumber can cause food poisoning due to infection of associated pathogens such as Vibrio parahaemolyticus [7, 8].

Most of the previous studies on A. japonicus have focused on the effects of abiotic factors, various dietary sources, 
and potential probiotics on its growth, immune system, and resistance to pathogens [9-12]. Recently, several studies analyzed the microbiota in sea cucumber using metagenomic technologies [13-15]. However, these studies specifically focused on the relationship between the gut microbiota and growth of A.japonicus, whereas the microbiota of the whole body of $A$. japonicus remains poorly characterized. Diverse microbes in the whole body of sea cucumber can act as potential agents of food poisoning through the intake of raw materials. Furthermore, the microbiota composition in sea cucumber can shift during storage and delivery to consumers, which will interact with infecting pathogens during the transportation process. Therefore, analysis of the whole-body microbiota of $A$. japonicus is necessary to understand the indigenous microbiota that will be associated with consumption of sea cucumber products, and determining the alterations of the microbiota during storage can provide insight into the effects of pathogens on the resident microbiota in sea cucumber.

Toward this end, we collected sea cucumbers at four sampling sites ( $n=5$ at each site) of Korea in August and November. The microbiota profiles were analyzed by Illumina MiSeq based on the 16S rRNA gene and compared among sites and sampling times. In addition, we conducted an artificial infection experiment with a pathogenic bacterium to directly observe the effects of pathogens on the resident microbiota in sea cucumber. These results can extend our understanding of the potential of food poisoning from the intake of sea cucumber, and help to better manage products for food safety and public health.

\section{Materials and Methods}

\section{Sample Collection}

A total of 40 sea cucumbers were collected from four different sites of Korea in November of 2015 (relatively low seawater temperature of $17.7 \pm 0.89^{\circ} \mathrm{C}$ ) and August of 2016 (relatively high seawater temperature of $25.3 \pm 1.61^{\circ} \mathrm{C}$ ) (Fig. 1). Five samples were randomly selected at each site and transported in ice boxes to the laboratory. The sampling sites were selected based on areas with maximum production in Korea, and the sampling months were chosen based on the season with maximum consumption (November) and minimum consumption (August) [16]. Bacterial cells were peeled off from chopped sea cucumber using a spindle (microorganism homogenizer, Korea patent registration: 10-20100034930). Rotation and vibration were performed using a direct drive motor in a stomach bag in the spindle. The bacterial cells obtained from each sample were diluted in buffered peptone water (10 $\mathrm{g}$ of peptone, $5 \mathrm{~g}$ of sodium chloride, $3.5 \mathrm{~g}$ of disodium phosphate, $1.5 \mathrm{~g}$ of $\mathrm{pH} 7.2$ potassium dihydrogen phosphate), and

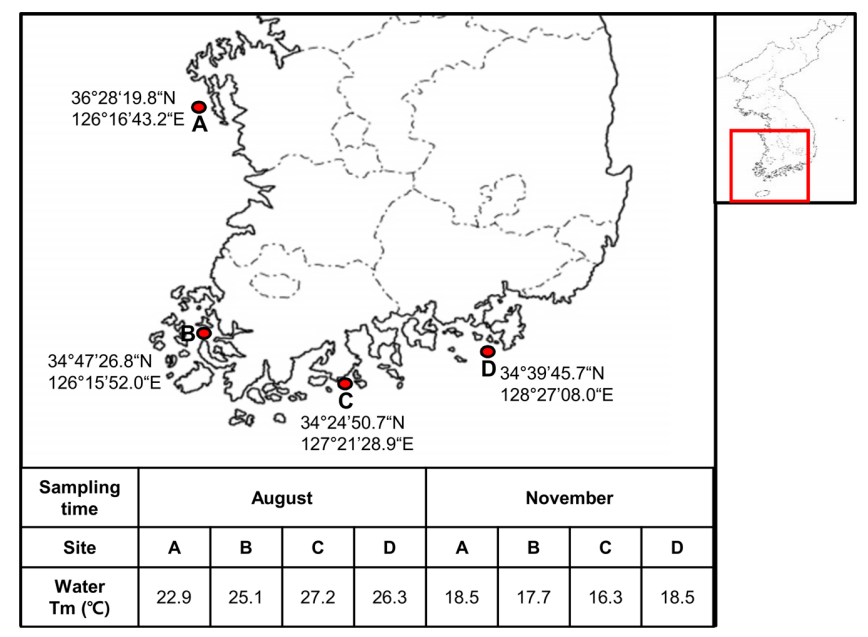

Fig. 1. Sampling sites of sea cucumber.

Samples were obtained from four different sites in August and November. The water temperature at the time of sampling is presented in the table below.

stored at $-80^{\circ} \mathrm{C}$ before DNA extraction.

\section{Experimental V.parahaemolyticus Infection Model}

To determine the influence of pathogen infection on the indigenous microbiota of sea cucumber during storage or delivery to consumers, we artificially infected sea cucumber with $V$. parahaemolyticus, and stored the samples in sterile containers at $27^{\circ} \mathrm{C}$ (room temperature condition) and $4^{\circ} \mathrm{C}$. V. parahaemolyticus FORC_018 was cultivated at $30^{\circ} \mathrm{C}$ in Luria-Bertani medium supplemented with $2 \% \mathrm{NaCl}$ to an optical density of 2.5 at $600 \mathrm{~nm}$. The infected cell number was $10^{4}$ colony-forming units/g, which is the infective dose of $V$. parahaemolyticus in seafood [17]. $V$. parahaemolyticus was sprayed evenly on the sea cucumber, and the temporal shifts of the sea cucumber microbiota were investigated after 1, 4, and $12 \mathrm{~h}$. Since the sea cucumber tended to decompose after $12 \mathrm{~h}$ of storage at $27^{\circ} \mathrm{C}$, we analyzed the microbiota up to this point. The microbiota of non-infected sea cucumber under the same conditions was also investigated as a negative control. The artificial infection experiments were performed in duplicate. Bacterial cells on the sea cucumber were collected as described above and stored at $-80^{\circ} \mathrm{C}$ before DNA extraction.

\section{Extraction of Metagenomic DNA}

The total metagenomic DNA of each sample was extracted using the phenol DNA extraction method as reported previously $[18,19]$. The final DNA pellet was resuspended in $100 \mu \mathrm{l}$ of TrisEDTA buffer and incubated at $37^{\circ} \mathrm{C}$ overnight. Extracted metagenomic DNA was purified with the PowerClean DNA Clean-up kit (Mo Bio Laboratories, USA). The extracted DNA was confirmed with $1 \%$ agarose gel electrophoresis, and the concentration was determined using an Eppendorf BioPhotometer 
D30 (Eppendorf, Germany). Four samples collected in November were excluded for further analysis owing to failure of DNA extraction.

\section{Real-Time Polymerase Chain Reaction (PCR)}

The bacterial amounts in sea cucumbers were measured by realtime PCR using TaKaRa PCR Thermal Cycler Dice Real Time System III (TaKaRa, Japan) as described previously [19, 20]. Triplicate reactions of each sample were conducted in a $25-\mu \mathrm{l}$ final volume containing $12.5 \mu \mathrm{l}$ of $2 \times$ SYBR Premix Ex Taq (TaKaRa), $2 \mu \mathrm{M}$ of each primer, and $1 \mu \mathrm{l}$ of DNA template (10-fold dilution series of sample DNA) or distilled water (negative control) under the following conditions: $95^{\circ} \mathrm{C}$ for $30 \mathrm{sec}$, followed by 40 cycles of denaturation at $95 \mathrm{C}$ for $30 \mathrm{sec}$, annealing at $60^{\circ} \mathrm{C}$ for $30 \mathrm{sec}$, extension at $72^{\circ} \mathrm{C}$ for $30 \mathrm{sec}$, and final extension at $72^{\circ} \mathrm{C}$ for $10 \mathrm{~min}$. Standard curves were generated from parallel PCRs of serial logconcentrations $\left(1 \times 10^{2}-1 \times 10^{8}\right)$ of $16 \mathrm{~S}$ rRNA gene copy numbers of the Escherichia coli K12 w3110 strain. Regression coefficients $\left(\mathrm{r}^{2}\right)$ for all standard curves were greater than 0.98 . The measured rRNA gene copy numbers were divided by 4.2 (the average copy number of the 16S rRNA gene in bacteria) for estimation of the total cell number [21]. The differences between samples were determined using the Mann-Whitney U-test in SPSS (ver. 21). Results with $p$ values of less than 0.05 were considered statistically significant.

The amounts of $V$. parahaemolyticus in the infection model were calculated by real-time PCR using the toxR gene primer [22]. Triplicate reactions of each sample were conducted using TaKaRa PCR Thermal Cycler Dice Real Time System III (TaKaRa) as described above. Standard curves were generated from parallel PCRs of serial log-concentrations $\left(1 \times 10^{2}-1 \times 10^{8}\right)$ of the V. parahaemolyticus FORC_018 strain. Regression coefficients $\left(\mathrm{r}^{2}\right)$ for all standard curves were greater than 0.99 .

\section{MiSeq Sequencing}

Metagenomic DNA from the samples was amplified using primers with an adapter (targeting the V1-V3 region of the 16S rRNA gene). The amplification was followed by the protocol for preparing a $16 \mathrm{~S}$ metagenomic sequencing library for the MiSeq system (Illumina, Inc., USA). Amplified products were verified by $2 \%$ agarose gel electrophoresis, and purification and size selection were performed using Agencourt AMPure XP beads (Beckman Coulter, USA). Then, index PCR was performed using the Nextera $\mathrm{XT}$ index kit following the manufacturer's instructions (Illumina, Inc.). The amplicons of each sample were purified by size selection using Agencourt AMPure XP beads (Beckman Coulter). The purified products were quantified using TaKaRa PCR Thermal Cycler Dice Real Time System III (TaKaRa). Equimolar concentrations of each library from the samples were pooled and sequenced using an Illumina MiSeq system (300-bp paired ends) according to the manufacturer's instructions at the Multidisciplinary Genome Institute in Hallym University.

\section{Sequence Data Analysis}

Sequence reads from the MiSeq sequencer were processed using the CLC Genomic Workbench (ver. 8.5.1) with the Microbial Genomics Module (Qiagen, USA). In brief, raw sequences of short read lengths ( $<200 \mathrm{bp} /$ pair) and low quality score $(\mathrm{Q}<25)$ were removed, and paired reads were merged with a mismatch score of overlap sequences. Primer sequences were removed from the merged sequences, and short read lengths were removed $(<430 \mathrm{bp}$ of merged reads). Chimeric sequences were removed using the UPARSE tool [23]. The sequences were then clustered to operational taxonomic units (OTUs) using the $97 \%$ sequence similarity based on the EzTaxon-e reference database [24]. The representative sequence in each OTU cluster was taxonomically assigned by the EzTaxon-e database. To compare the diversity indices among samples, the number of reads in each sample was normalized by random subsampling, and calculated using the Mothur program [25]. Principal coordinate analysis (PCoA) based on the weighted and unweighted UniFrac distances was conducted to compare the microbiota among samples. A Circos plot was made using the Circos Web tool (http://mkweb.bcgsc.ca/ tableviewer). The differences among samples were analyzed using the Kruskal-Wallis test, and the differences between samples were analyzed again using the Mann-Whitney U-test in SPSS (ver. 21). Results with a $p$ value of less than 0.05 were considered statistically significant. The sequence reads in this study were submitted to the EMBL SRA database under study number PRJEB21905 (https://www.ebi.ac.uk/ena/data/view/ PRJEB21905).

\section{Results and Discussion}

\section{Comparison of Bacterial Amounts and Diversity Indices among Samples}

The bacterial amounts in sea cucumber were compared between sampling times and sites (Fig. 2A). The total amounts of bacterial loads in the sea cucumber samples in August (average, $2.12 \times 10^{7}$ cells $/ g$ ) were significantly higher than those in November $\left(2.24 \times 10^{5}\right.$ cells $\left./ g ; p<0.001\right)$. The highest bacterial amounts were detected in samples of site $B$ at both sampling times $\left(4.29 \times 10^{7}\right.$ cells $/ g$ in August and $6.81 \times 10^{5}$ cells $/ g$ in November). The lowest bacterial loads in sea cucumber were detected in site A at both sampling times $\left(7.39 \times 10^{6}\right.$ cells $/ g$ in August and $5.09 \times 10^{4}$ cells $/ g$ in November). The largest difference between sampling times was found in samples of site D $\left(1.50 \times 10^{7}\right.$ cells $/ g$ in August and $5.52 \times 10^{4}$ cells $/ g$ in November).

A total of $4,491,977$ reads $(2,418,546$ reads from samples in August and 2,073,431 reads from samples in November) were analyzed after trimming processes. To compare the diversity indices among samples, the read numbers of each 
A
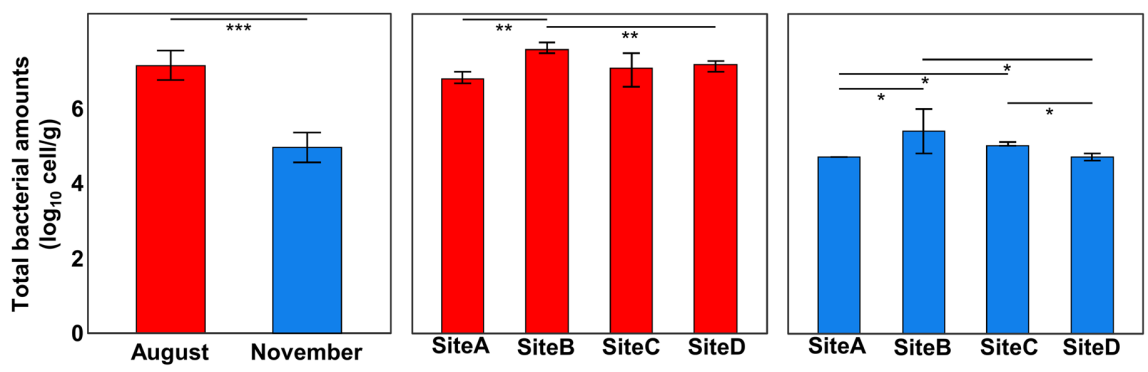

B
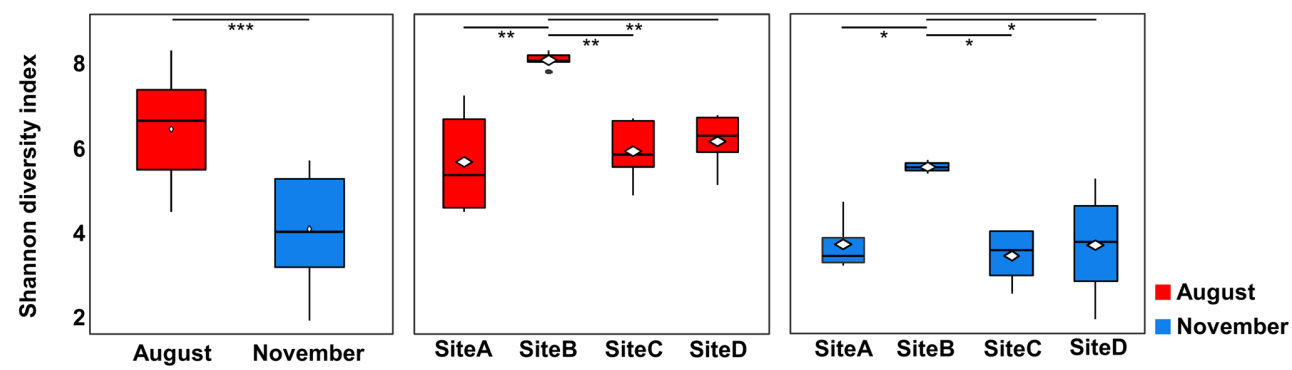

Fig. 2. Bacterial amounts and diversity in sea cucumber from different sites and sampling times.

(A) The amount of bacteria was estimated by real-time PCR. The average bacterial amounts in sea cucumber were compared among sampling sites and times. Error bars indicate the standard deviation. (B) Comparison of Shannon diversity indices of samples from different sites and times. ${ }^{*} p<$ $0.05,{ }^{* *} p<0.01, * * * p<0.001$.

sample were normalized to 25,000 by random subsampling (Table S1). The average numbers of observed OTUs were higher in the August samples $(7,318.0 \pm 3,132.4)$ than in the November samples $(2,504.6 \pm 1,230.9 ; p<0.001)$. The highest number of OTUs was detected in site B in August $(11,985.2 \pm 554.8)$, whereas the lowest number was found in site $C$ in November $(1,520.5 \pm 523.7)$. The numbers of observed OTUs in sea cucumber samples collected from site B were relatively higher than those in the other sites at both sampling times. The Shannon diversity indices were compared between seasons and sampling sites (Fig. 2B). Overall, the microbiota in sea cucumber was more diverse in August than in November $(p<0.001)$. Consistent with the calculated cell numbers, the highest diversity indices were detected in samples of site B, whereas the lowest were detected in samples of site A. Therefore, the number of bacteria was related to the bacterial diversity in sea cucumber. Although the bacterial amounts and diversity were higher in samples from site $B$, a higher water temperature was detected in site $\mathrm{C}$ in August $\left(27.2^{\circ} \mathrm{C}\right)$ and at sites $\mathrm{A}$ and $\mathrm{D}$ in November $\left(18.5^{\circ} \mathrm{C}\right)$ (Fig. 1). Site $\mathrm{A}$ is located at the most northern coast of all sites, and site $B$ is surrounded by islands. In addition, site B is characterized by shallow water depths $(<50 \mathrm{~m})$, relatively strong tidal currents $(1-2 \mathrm{~m} / \mathrm{s})$, and complicated coastlines with numerous islands and more extensive tidal flats than the other sampling sites [26]. This suggests that the colonization of indigenous bacteria in sea cucumber could be affected by environmental factors other than water temperature.

\section{Comparison of Microbiota Composition between November and August at Each Site}

The PCoA plots based on unweighted and weighted UniFrac distances showed clear differences in the microbiota of sea cucumber between August and November (Fig. 3). Using the weighted UniFrac distances, clear differences among sampling sites were found among the August samples. Sites B and D clustered together in August, but were more similar to samples from other sites in November. These differences were in line with the variations in bacterial amounts and diversity between August and November (Fig. 2).

At the phylum level, Proteobacteria was the dominant phylum in the majority of samples, and its abundance was highest in samples from sites A (72.2\%) and C (73.6\%) in August, whereas it was most abundant in samples from sites B (77.1\%) and D (73.3\%) in November (Fig. 3B). The proportions of Proteobacteria were decreased in samples from sites $A$ and $C$ in November, whereas they were increased in samples from sites B and D. This result confirmed that the sea cucumber microbiota varies geographically.

Verrucomicrobia and Bacteroidetes were the next most dominant phyla in August (13.4\%) and November (32.5\%), 
A

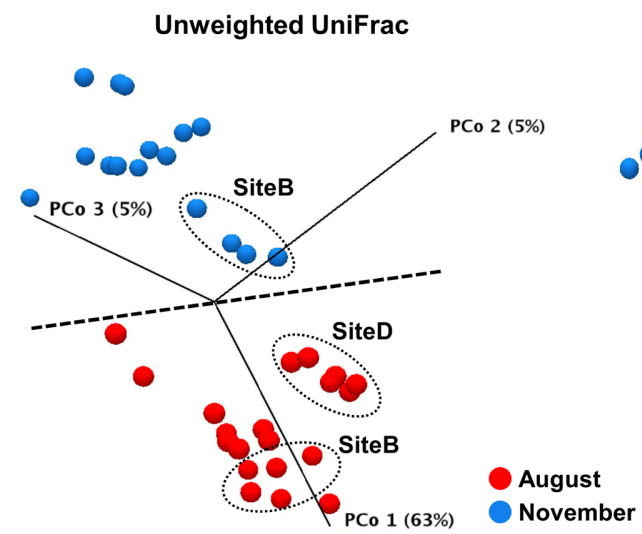

Weighted UniFrac

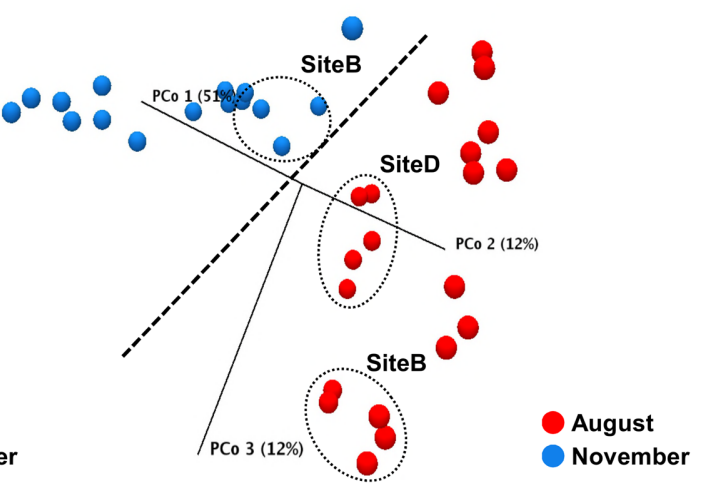

B

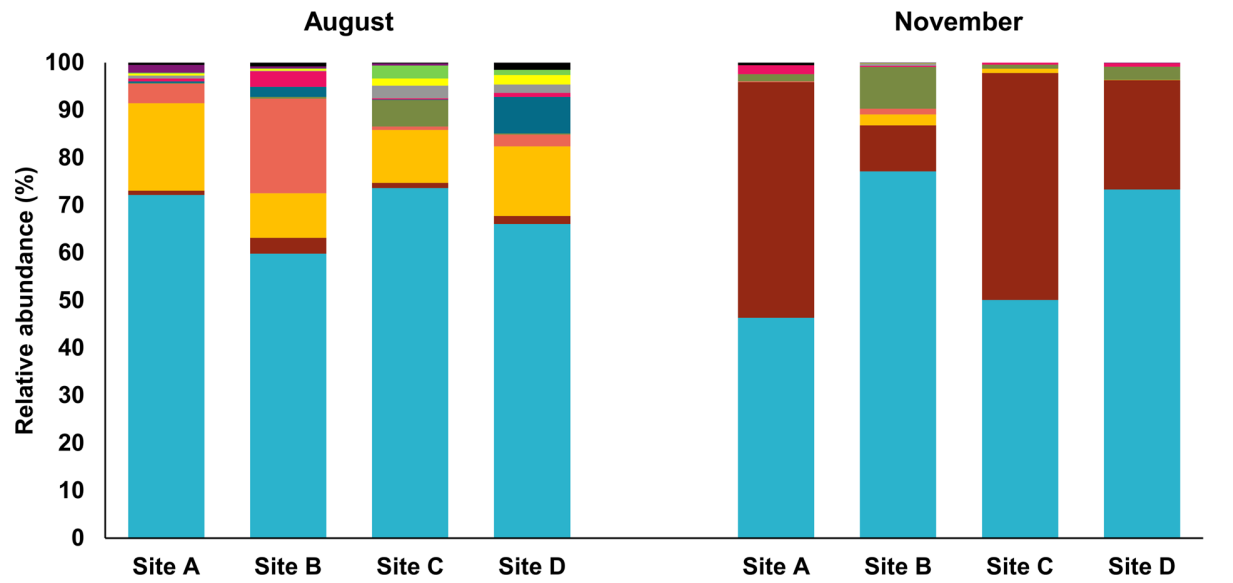

- Others

- Acidobacteria

$\square$ Spirochaetes

Cyanobacteria

- Uncultured Bacteria

- Actinobacteria

- Chloroflexi

Firmicutes

- Planctomycetes

- Verrucomicrobia

- Bacteroidetes

- Proteobacteria

Fig. 3. Comparison of microbiota among sampling sites and times.

(A) PCoA plots of microbiota in sea cucumber obtained at different sampling times and sites. PCoA plots were obtained on the basis of unweighted UniFrac distance (left) and weighted UniFrac distance (right). Red circles indicate the microbiota in sea cucumber collected in August 2016, and blue circles indicate the microbiota in sea cucumber collected in November 2015. (B) Comparison of bacterial communities at the phylum level. The average proportions of phyla were obtained from samples in each site, and phyla with a relative abundance of $<1 \%$ in each sample were combined to the "others" group.

respectively. The proportions of Bacteroidetes were highest in samples from sites $\mathrm{A}$ and $\mathrm{C}$ in November. The dominance of Proteobacteria, Verrucomicrobia, and Bacteroidetes in the sea cucumber gut was also found in previous studies $[13,14]$. Although the phylum composition was different between August and November, the microbiota in samples from site B was consistently distinct from that of the other sites at each sampling time. This difference could be related to the relatively higher diversity and bacterial amounts of samples from site B (Fig. 2). Planctomycetes and Firmicutes were the dominant phyla in samples from site B in August and November. These two phyla were also detected in a previous $A$. japonicus gut microbiota study [14]. Although Proteobacteria was the dominant phylum at both sampling times, the dominant class within Proteobacteria differed over time (Fig. S1). Alpha- and Betaproteobacteria were the dominant classes in August samples, whereas Gamma- and Betaproteobacteria were dominant in November samples. Alpha- and Gammaproteobacteria were detected in the gut and surrounding sediments of sea cucumbers in previous studies [13, 14]. Nevertheless, Betaproteobacteria was detected as the dominant class in sea cucumber at both sampling times in the present study. Betaproteobacteria members have been found in marine environments, where they play a role in biological nitrogen fixation and biodegradation of various compounds [27, 28]. The dominance of Betaproteobacteria as well as Gamma- and Alphaproteobacteria demonstrated that the microbiota results in this study reflected the whole body of sea cucumber, including gut contents. Flavobacteria was the predominant class in November samples, which was also previously reported to be a dominant member of the gut microbiota of sea cucumber [15]. 
The dominant genera $(>0.5 \%$ of the microbiota in at least one sample) were compared between sites and sampling times (Fig. S2). The detected number of genera was higher in August (426) than in November (130). The difference of genera composition between sampling sites was also higher in August than in November. In the August samples, Burkholderia and Rubritalea were the commonly dominant genera, which had the highest proportions at site D (46.1\%, $p<0.01)$, and at sites A (18.3\%) and D (14.2\%), respectively. Burkholderia (within Betaproteobacteria) was also detected in a previous sea cucumber study [14], and Rubritalea was found as carotenoid- and squalene-producing bacteria in a marine environment [29]. The relative abundance of Pseudahrensia was highest at site A $(42.0 \%, p<0.01)$, uncultured Rhodobacteraceae was most abundant at site B (25.6\%, $p<0.01)$, and uncultured Rhodospirillaceae was most abundant at site C $(21.6 \%, p<0.01)$. Pseudahrensia species were also detected in the gut of a Japanese flying squid and in seawater [30, 31], indicating that these bacteria are likely common in seawater and sea animals. In the November samples, the dominant genera were similar between sampling sites except for site B. Psychrobacter and Paraburkholderia were the dominant genera at site B $(p<$ 0.05), whereas Flavobacterium, Enterobacter, and Burkholderia were dominant genera at the other sites. Psychrobacter species are psychrophilic bacteria that have been found in marine environments [32]. Since the temperature of seawater decreased during winter, the proportion of Psychrobacter would be expected to increase after November. Flavobacterium and Enterobacter are the common genera in the gut of aquatic invertebrates, including sea cucumber [33]. Overall, the difference of microbiota in sea cucumber among sampling sites was higher in August than in November.

\section{Detected Potential Pathogens in Sea Cucumbers}

To determine the potential pathogens in sea cucumber samples, the bacterial sequences were compared with known pathogenic bacteria in the PATRIC database (http:/ / www.patricbrc.org). The detected potential pathogens were compared between sampling sites and time (Fig. S3). The detected number of potential pathogens was higher in August samples (30 species) than in November samples (25 species), and the specific pathogens differed among sampling sites. The relative abundances of potential pathogens were higher in samples from site C $(4.1 \%$ of total microbiota) in August, and Staphylococcus warneri (3.23\%) and Staphylococcus sciuri $(0.62 \%)$ were most abundant at this site. S. warneri was a commonly detected potential pathogen in both the August and November samples, which can cause bacteremia and septic arthritis [34, 35]. S. sciuri was detected only in the August samples, and has been reported to be associated with several human diseases such as endocarditis, peritonitis, septic shock, and wound infections [36-38]. The proportions of Propionibacterium acnes and Chryseobacterium indologenes were higher in November than in August. P. acnes was detected in all sites of November samples. This bacterium is generally considered a non-pathogenic or low-virulence pathogen; however, a few studies have shown its association with chronic inflammation and systemic infections [39, 40]. C. indologenes has been detected in food and water sources, and is usually associated with hospital-acquired infections such as a nosocomial transinfection and sepsis [41, 42]. The proportions of detected potential pathogens were higher in November than in August at all sites except at site C. Although the detected proportions of potential pathogens were relatively low ( $<1.5 \%$ in November, $<4.1 \%$ in August), the higher proportion of potential pathogens in November than in August at most of sites indicates that the ingestion of sea cucumber is also a risk in November despite the relatively low water temperature. However, since the present detection was based only on the 16S rRNA gene, further studies are needed to clarify the pathogenicity of these bacteria using other methods.

\section{Effects of V. parahaemolyticus Infection on Indigenous Microbiota of Sea Cucumber Over Time}

The effects of pathogen infection on the indigenous microbiota of sea cucumber during storage or delivery to consumers were evaluated by artificial infection experiments. $V$. parahaemolyticus is a causative agent of acute gastroenteritis in humans who consume raw or undercooked fish and shellfish, and was reported to be isolated from cultured sea cucumber, indicating its potential for infection after the intake of raw sea cucumber [8]. Therefore, we analyzed the effects of $V$. parahaemolyticus on the indigenous microbiota of sea cucumber to simulate the transportation and storage processes.

The bacterial amounts and diversity were compared between non-infected and infected samples over time at different temperatures (Figs. $4 \mathrm{~A}$ and 4B). Total bacterial cells in sea cucumber decreased after $1 \mathrm{~h}$ in all samples, which indicated that the indigenous bacteria in sea cucumber could not maintain their biomass during storage regardless of pathogen infection. However, the total amount of bacteria increased after $4 \mathrm{~h}$ only in the infected samples stored at $27^{\circ} \mathrm{C}\left(1.68 \times 10^{5}\right.$ cells/g after $\left.12 \mathrm{~h}\right)$. By contrast, the diversity of microbiota increased during 

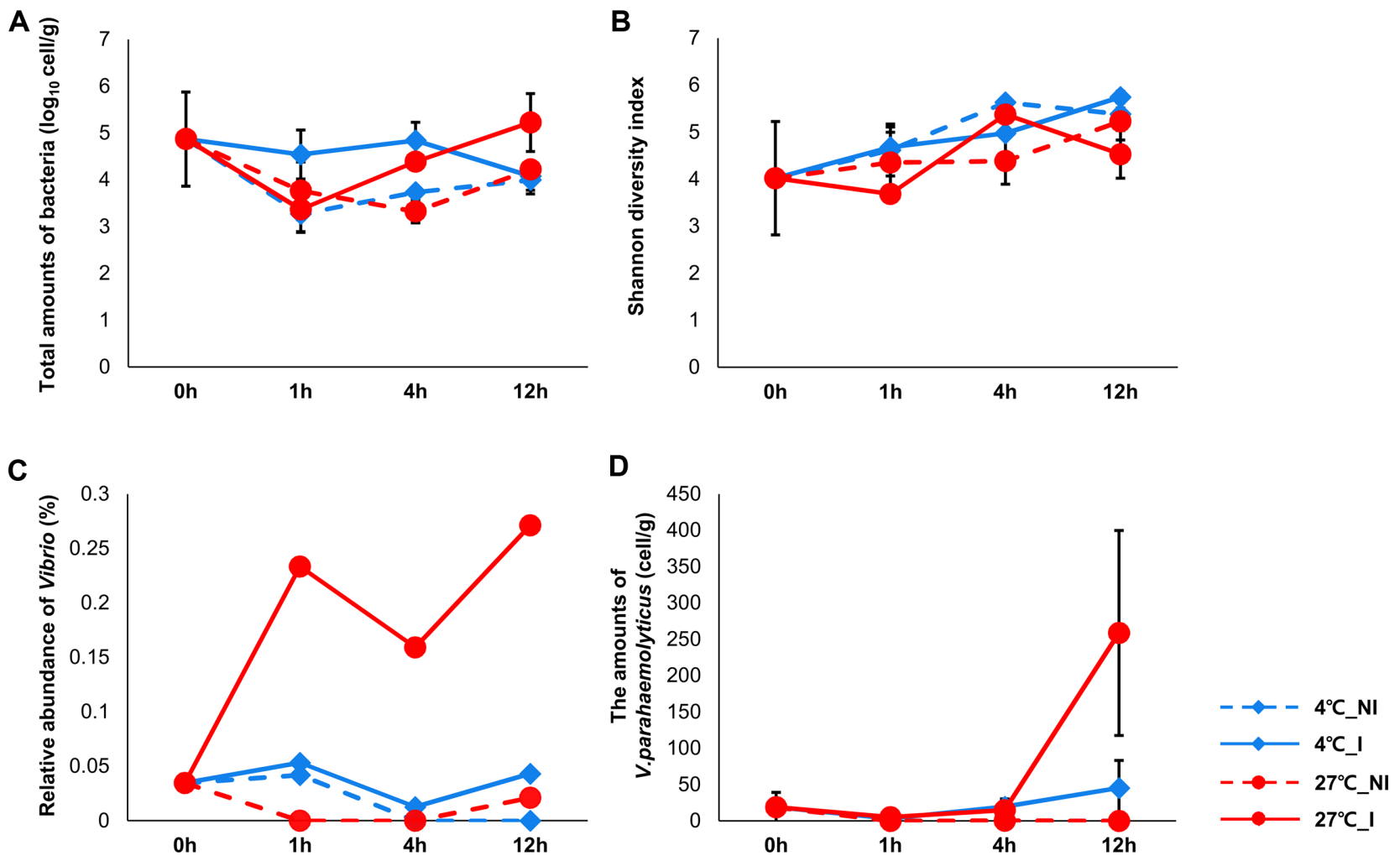

Fig. 4. Effects of Vibrio parahaemolyticus infection on indigenous microbiota of sea cucumber.

(A) Bacteria amounts, (B) Shannon diversity indices, (C) proportion of Vibrio, and (D) amounts of V. parahaemolyticus among samples of noninfected sea cucumber stored at $4^{\circ} \mathrm{C}\left(4^{\circ} \mathrm{C} \_\right.$NI, blue diamond with dashed line), infected by $V$. parahaemolyticus sea cucumber stored at $4^{\circ} \mathrm{C}\left(4^{\circ} \mathrm{C} \_\mathrm{I}\right.$, blue diamond with solid line), non-infected sea cucumber stored at room temperature $\left(27^{\circ} \mathrm{C} \_\mathrm{NI}\right.$, red circle with dashed line), and infected sea cucumber stored at room temperature $\left(27^{\circ} \mathrm{C}_{-} \mathrm{I}\right.$, red circle with solid line). Error bars indicate the standard deviation.

storage, suggesting a decrease in the cell numbers of dominant members of the microbiota over time. The diversity of infected samples at $27^{\circ} \mathrm{C}$ was lower than that of the other samples after $12 \mathrm{~h}$. This result could be due to the good growth of $V$. parahaemolyticus in this condition, leading to a decrease in the microbiota diversity. This increase in $V$. parahaemolyticus was also reflected by an increase in the proportion of the Vibrio genus and real-time PCR results over time (Figs. $4 \mathrm{C}$ and $4 \mathrm{D}$ ). However, these increases were only detected in the infected samples at $27^{\circ} \mathrm{C}$, which reflects the optimal growth temperature of Vibrio $\left(17-35^{\circ} \mathrm{C}\right)$ [43].

The shifts of microbiota were analyzed and compared among different conditions at the phylum level (Fig. S4). At $0 \mathrm{~h}$ after infection, Proteobacteria was the predominant phylum, followed by Verrucomicrobia. The proportion of Proteobacteria then decreased in both the non-infected and infected samples at $4^{\circ} \mathrm{C}$ over time, whereas the relative abundance of Verrucomicrobia and Planctomycetes increased in these samples. The proportion of Proteobacteria was similar between the non-infected and infected samples at $27^{\circ} \mathrm{C}$ over time, but decreased more strongly in the noninfected samples $(78.1 \%$ after $12 \mathrm{~h})$ than in the infected samples $(72.7 \%$ after $12 \mathrm{~h})$. This difference could reflect the effects of Vibrio on the microbiota of infected samples. Although the proportion of Verrucomicrobia also increased in these conditions, its proportion was smaller in samples at $27^{\circ} \mathrm{C}(9.0 \%$ after $12 \mathrm{~h})$ than at $4^{\circ} \mathrm{C}(19.6 \%$ after $12 \mathrm{~h})$. The proportion of Firmicutes increased in both infected and non-infected samples at $27^{\circ} \mathrm{C}$. These results further demonstrated the different effects of $V$. parahaemolyticus on indigenous microbiota depending on storage conditions.

The shifts of microbiota in each condition were further evaluated according to the changes in the dominant genera (Fig. 5). The proportions of Moraxella and Psychrobacter decreased in both the non-infected and infected samples at $4^{\circ} \mathrm{C}$, but Psychrobacter decreased more in the infected samples $(12.0 \%)$ than in the non-infected samples $(16.7 \%)$ 

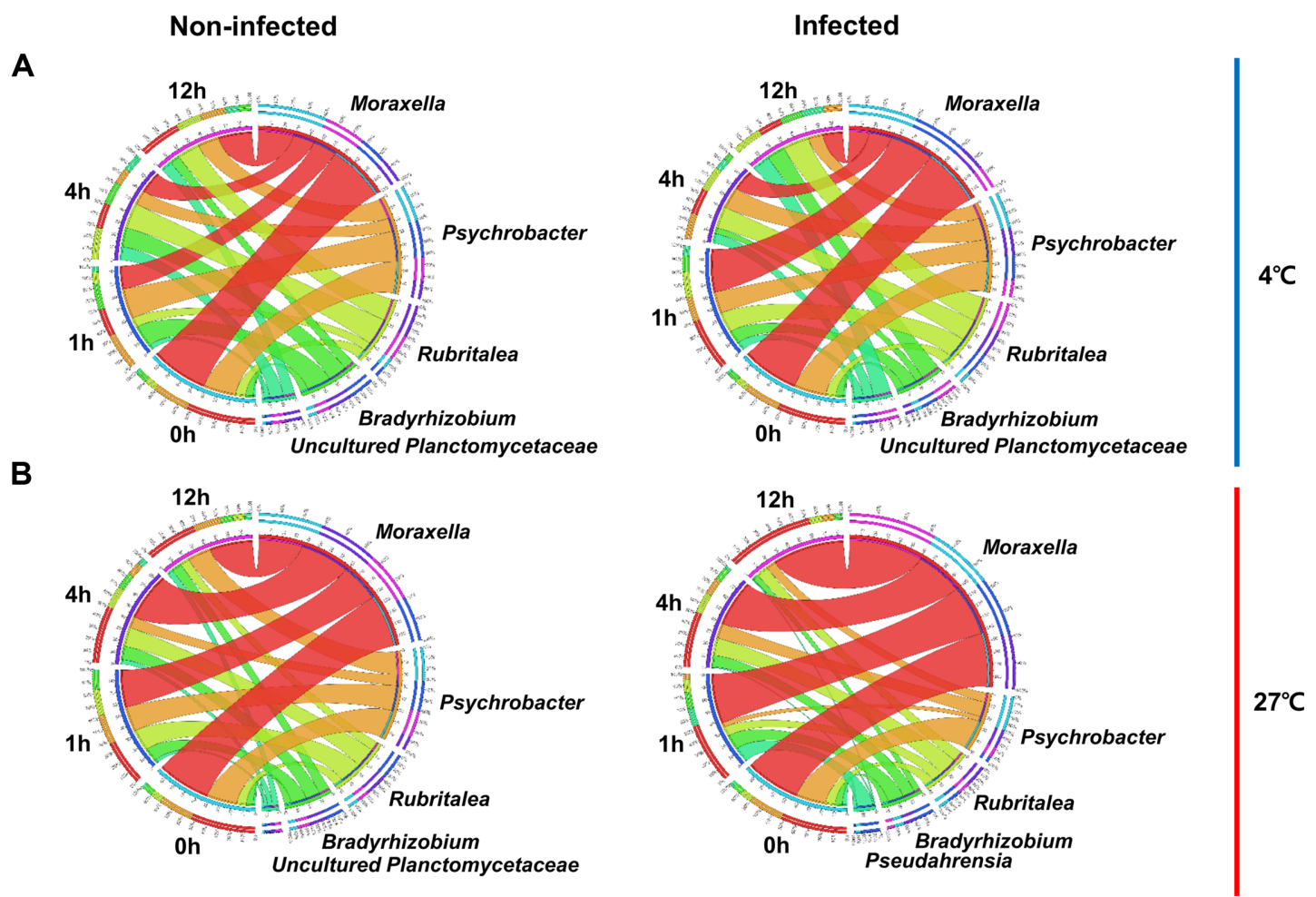

$27^{\circ} \mathrm{C}$

Fig. 5. The shifts of dominant genera following experimental infection with Vibrio parahaemolyticus among different conditions, presented using Circos plots.

(A) Comparison of dominant genera among samples of non-infected (left) and infected (right) sea cucumbers stored at $4^{\circ} \mathrm{C}$. (B) Comparison of dominant genera among samples of non-infected (left) and infected (right) sea cucumbers stored at room temperature $\left(27^{\circ} \mathrm{C}\right)$. In the outer layer, the different colors of sample segments (left) represent the dominant genera in each sample with the proportion presented in descending order. The different colors of the genus segment (right) indicate the distribution of each genus in the sea cucumber samples. In the inner layer, each different color represents a different sample and genus, and the numbers beside the axis indicate the relative abundance of the corresponding samples and genera. The width of the ribbons connecting the sample and genus segments indicates the proportion of the corresponding genera.

after $12 \mathrm{~h}$. The shifts of Rubritalea, Bradyrhizobium, and Uncultured Planctomycetaceae were similar in both the infected and non-infected samples. Although the proportion of Moraxella was similar in the non-infected and infected samples until $4 \mathrm{~h}$ at $27^{\circ} \mathrm{C}$, it became higher in infected samples $(60.6 \%$ vs. $37.1 \%)$ after $12 \mathrm{~h}$. The proportion of Psychrobacter also decreased more in infected samples $(8.0 \%)$ than in non-infected samples $(19.9 \%)$ after $12 \mathrm{~h}$. In a previous study, Psychrobacter sp. showed a beneficial effect on the growth, osmotic stress resistance, immunity, and disease resistance of white shrimp [44]. In addition, Moraxella was frequently isolated from diseased sea cucumber [45]. Therefore, the alterations of Moraxella and Psychrobacter can be candidate indicators for infection of Vibrio during storage or delivery.

Analysis of the bacterial microbiota in the whole sea cucumber body revealed clear variations in compositions between sampling times and sites. Alpha-, Beta-, and Gammaproteobacteria were the common dominant classes in sea cucumber. Although the diversity of microbiota and bacterial amounts in sea cucumber were influenced by sampling time with relatively high temperature, the surrounding environmental factors of sampling sites appear to have a greater influence. The potential pathogens detected in the present study (S. warneri, S. sciuri, P. acnes, and C. indologenes) can be used to screen for pathogens in sea cucumber, and alterations of Psychrobacter and Moraxella in the microbiota of sea cucumber can be applied as indicators of infection by $V$. parahaemolyticus. Further studies are needed to understand the pathogenicity and interactions of the microbiota detected in sea cucumber. Nevertheless, these results can serve as a guide to develop management and monitoring strategies for sea cucumber products to improve food safety with sea cucumber consumption. 


\section{Acknowledgments}

This study was supported by the Ministry of Food and Drug Safety, Republic of Korea in 2016 (14162MFDS972) and Hallym University Research Fund, 2016 (HRF-201612011).

\section{References}

1. Purcell SW, Samyn Y, Conand C. 2012. Commercially important sea cucumbers of the world. FAO Species Catalogue for Fishery Purposes, No. 6. FAO, Rome.

2. Choo PS. 2008. Population status, fisheries and trade of sea cucumbers in Asia. Sea cucumbers: a global review of fisheries and trade, pp. 81-118. In Toral-Granda V, Lovatelli A, Vasconcellos M (eds.), FAO Fisheries and Aquaculture Technical Paper, No. 516. FAO, Rome.

3. Nagase H, Kitazato KT, Sasaki E, Hattori M, Kitazato K, Saito H. 1997. Antithrombin III-independent effect of depolymerized holothurian glycosaminoglycan (DHG) on acute thromboembolism in mice. Thromb. Haemost. 77: 399-402.

4. Fan H. 2001. Sea cucumber: research and development on the health care functioning of sea cucumber and its ingredients. Chin. Mar. Med. 4: 37-42.

5. Hamel JF, Mercier A. 2013. Apostichopus japonicus. Available from http://www.iucnredlist.org/details/full/180424/0. Accessed December 2016.

6. Lovatelli A, Conand S, Purcell S, Uthicke S, Hamel JF, Mercier A. 2004. Advances in sea cucumber aquaculture and management. FAO Fisheries Technical Paper, No. 463. FAO, Rome.

7. King GM, Judd C, Kuske CR, Smith C. 2012. Analysis of stomach and gut microbiomes of the eastern oyster (Crassostrea virginica) from coastal Louisiana, USA. PLoS One 7: e51475.

8. Jiang Y, Yao L, Li F, Tan Z, Zhai Y, Wang L. 2014. Characterization of antimicrobial resistance of Vibrio parahaemolyticus from cultured sea cucumbers (Apostichopus japonicas). Lett. Appl. Microbiol. 59: 147-154.

9. Jeong U, Jin F, Choi J, Han J, Choi B, Kang S. 2016. A laboratory-scale recirculating aquaculture system for sea cucumber Apostichopus japonicus. Korean J. Fish. Aquat. Sci. 49: 343-350. [In Korean]

10. Seo J, Shin I, Lee S. 2011. Effect of dietary inclusion of various plant ingredients as an alternative for Sargassum thunbergii on growth and body composition of juvenile sea cucumber Apostichopus japonicus. Aquacult. Nutr. 17: 549-556.

11. Yang ZP, Sun JM, Xu Z, Zhang CC, Zhou Q. 2014. Beneficial effects of Metschnikowia sp. C14 on growth and intestinal digestive enzymes of juvenile sea cucumber Apostichopus japonicus. Anim. Feed Sci. Technol. 197: 142-147.

12. Zhao Y, Zhang W, Xu W, Mai K, Zhang Y, Liufu Z. 2012. Effects of potential probiotic Bacillus subtilis T13 on growth, immunity and disease resistance against Vibrio splendidus infection in juvenile sea cucumber Apostichopus japonicus. Fish Shellfish Immunol. 32: 750-755.

13. Gao F, Li F, Tan J, Yan J, Sun H. 2014. Bacterial community composition in the gut content and ambient sediment of sea cucumber Apostichopus japonicus revealed by 16S rRNA gene pyrosequencing. PLoS One 9: e100092.

14. Sha Y, Liu M, Wang B, Jiang K, Sun G, Wang L. 2016. Gut bacterial diversity of farmed sea cucumbers Apostichopus japonicus with different growth rates. Microbiology 85: 109-115.

15. Yang G, Xu Z, Tian X, Dong S, Peng M. 2015. Intestinal microbiota and immune related genes in sea cucumber (Apostichopus japonicus) response to dietary beta-glucan supplementation. Biochem. Biophys. Res. Commun. 458: 98-103.

16. Korean Statistical Information Service (KOSIS). 2017. Fishery production survey. Available from http://kosis.kr/eng/ statisticList/. Accessed December 2016.

17. Interstate Shellfish Sanitation Conference (ISSC). 1997. National Shellfish Sanitation Program: Guide for the Control of Molluscan Shellfish. Washington, DC.

18. Naravaneni R, Jamil K. 2005. Rapid detection of food-borne pathogens by using molecular techniques. J. Med. Microbiol. 54: 51-54.

19. Lee MJ, Lee JJ, Chung HY, Choi SH, Kim BS. 2016. Analysis of microbiota on abalone (Haliotis discus hannai) in South Korea for improved product management. Int. J. Food Microbiol. 234: 45-52.

20. Chang S, Cui X, Guo M, Tian Y, Xu W, Huang K, et al. 2017. Insoluble dietary fiber from pear pomace can prevent highfat diet-induced obesity in rats mainly by improving the structure of the gut microbiota. J. Microbiol. Biotechnol. 27: 856-867.

21. Vetrovsky T, Baldrian P. 2013. The variability of the $16 \mathrm{~S}$ rRNA gene in bacterial genomes and its consequences for bacterial community analyses. PLoS One 8: e57923.

22. Neogi SB, Chowdhury N, Asakura M, Hinenoya A, Haldar S, Saidi SM, et al. 2010. A highly sensitive and specific multiplex PCR assay for simultaneous detection of Vibrio cholerae, Vibrio parahaemolyticus and Vibrio vulnificus. Lett. Appl. Microbiol. 51: 293-300.

23. Edgar RC. 2013. UPARSE: highly accurate OTU sequences from microbial amplicon reads. Nat. Methods 10: 996-998.

24. Kim OS, Cho YJ, Lee K, Yoon SH, Kim M, Na H, et al. 2012. Introducing EzTaxon-e: a prokaryotic $16 \mathrm{~S}$ rRNA gene sequence database with phylotypes that represent uncultured species. Int. J. Syst. Evol. Microbiol. 62: 716-721.

25. Schloss PD, Westcott SL, Ryabin T, Hall JR, Hartmann M, Hollister EB, et al. 2009. Introducing mothur: open-source, platform-independent, community-supported software for describing and comparing microbial communities. Appl. Environ. Microbiol. 75: 7537-7541.

26. Min J, Choi J, Yang H, Lee S, Ryu J. 2014. Monitoring changes in suspended sediment concentration on the southwestern 
coast of Korea. J. Coastal Res. 70: 133-138.

27. Donn S, Kirkegaard JA, Perera G, Richardson AE, Watt M. 2015. Evolution of bacterial communities in the wheat crop rhizosphere. Environ. Microbiol. 17: 610-621.

28. Perez-Pantoja D, Donoso R, Agullo L, Cordova M, Seeger M, Pieper DH, et al. 2012. Genomic analysis of the potential for aromatic compounds biodegradation in Burkholderiales. Environ. Microbiol. 14: 1091-1117.

29. Yoon J, Matsuo Y, Matsuda S, Adachi K, Kasai H, Yokota A. 2007. Rubritalea spongiae sp. nov. and Rubritalea tangerina sp. nov., two carotenoid- and squalene-producing marine bacteria of the family Verrucomicrobiaceae within the phylum 'Verrucomicrobia', isolated from marine animals. Int. J. Syst. Evol. Microbiol. 57: 2337-2343.

30. Kim HS, Kim PS, Hyun DW, Lee JY, Kang W, Shin NR, et al. 2016. Pseudahrensia todarodis sp. nov., isolated from the gut of a Japanese flying squid, Todarodes pacificus. Int. J. Syst. Evol. Microbiol. 66: 1389-1393.

31. Jung YT, Park S, Lee JS, Oh TK, Yoon JH. 2012. Pseudahrensia aquimaris gen. nov., sp. nov., isolated from seawater. Int. J. Syst. Evol. Microbiol. 62: 2056-2061.

32. Romanenko LA, Schumann P, Rohde M, Lysenko AM, Mikhailov VV, Stackebrandt E. 2002. Psychrobacter submarinus sp. nov. and Psychrobacter marincola sp. nov., psychrophilic halophiles from marine environments. Int. J. Syst. Evol. Microbiol. 52: 1291-1297.

33. Harris JM. 1993. The presence, nature, and role of gut microflora in aquatic invertebrates: a synthesis. Microb. Ecol. 25: 195-231.

34. Kamath U, Singer C, Isenberg HD. 1992. Clinical significance of Staphylococcus warneri bacteremia. J. Clin. Microbiol. 30: 261-264.

35. Legius B, Landuyt KV, Verschueren P, Westhovens R. 2012. Septic arthritis due to Staphylococcus warneri: a diagnostic challenge. Open Rheumatol. J. 6: 310-311.

36. Horii T, Suzuki Y, Kimura T, Kanno T, Maekawa M. 2001.
Intravenous catheter-related septic shock caused by Staphylococcus sciuri and Escherichia vulneris. Scand. J. Infect. Dis. 33: 930-932.

37. Hedin G, Widerstrom M. 1998. Endocarditis due to Staphylococcus sciuri. Eur. J. Clin. Microbiol. Infect. Dis. 17: 673-675.

38. Stepanovic S, Dakic I, Djukic S, Lozuk B, Svabic-Vlahovic M. 2002. Surgical wound infection associated with Staphylococcus sciuri. Scand. J. Infect. Dis. 34: 685-686.

39. Ishige I, Usui Y, Takemura T, Eishi Y. 1999. Quantitative PCR of mycobacterial and propionibacterial DNA in lymph nodes of Japanese patients with sarcoidosis. Lancet 354: 120-123.

40. Stirling A, Worthington T, Rafiq M, Lambert PA, Elliott TS. 2001. Association between sciatica and Propionibacterium acnes. Lancet 357: 2024-2025.

41. Chen FL, Wang GC, Teng SO, Ou TY, Yu FL, Lee WS. 2013. Clinical and epidemiological features of Chryseobacterium indologenes infections: analysis of 215 cases. J. Microbiol. Immunol. Infect. 46: 425-432.

42. McKew G. 2014. Severe sepsis due to Chryseobacterium indologenes in an immunocompetent adventure traveler. $J$. Clin. Microbiol. 52: 4100-4101.

43. Cervino JM, Hayes RL, Polson SW, Polson SC, Goreau TJ, Martinez RJ, et al. 2004. Relationship of Vibrio species infection and elevated temperatures to yellow blotch/band disease in Caribbean corals. Appl. Environ. Microbiol. 70: 6855-6864.

44. Franco R, Arenal A, Martin L, Martinez Y, Santiesteban D, Sotolongo J, et al. 2016. Psychrobacter sp. 17-1 enhances growth and survival in early postlarvae of white shrimp, Penaeus vannamei Boone, 1931 (Decapoda, Penaeidae). Crustaceana 89: 1467-1484.

45. Li H, Qiao G, Gu JQ, Zhou W, Li Q, Woo SH, et al. 2010. Phenotypic and genetic characterization of bacteria isolated from diseased cultured sea cucumber Apostichopus japonicus in northeastern China. Dis. Aquat. Organ. 91: 223-235. 